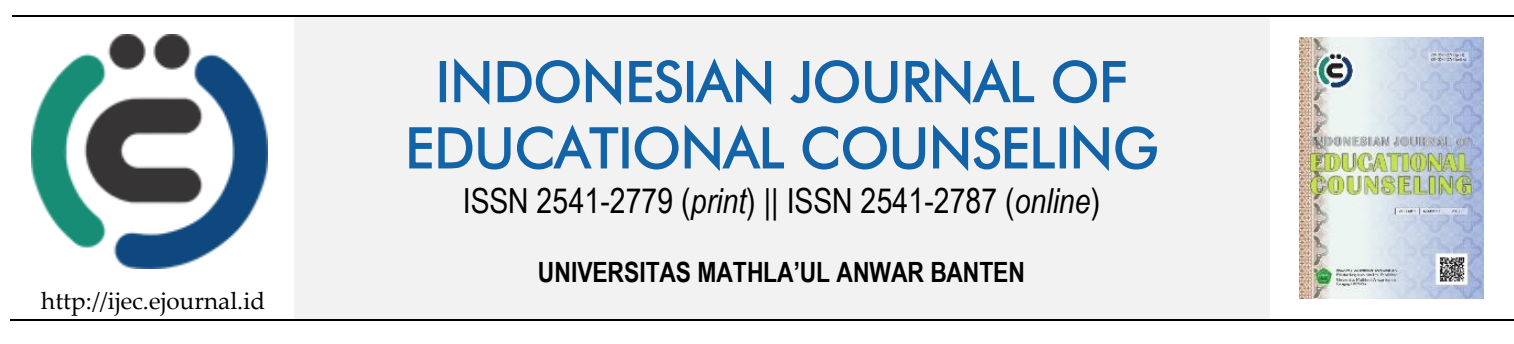

Research Based Article

\title{
Sikap Peserta Diklat PIM Tingkat IV terhadap Model Pembelajaran Blended Learning
}

Ratnaningsih Hidayati ${ }^{1}$, Nadya Megawati Rachman², Caterin Magdalena Simamora ${ }^{2}$

1,2 Pusat Pendidikan dan Pelatihan Perdagangan Kementerian Perdagangan RI

\begin{tabular}{ll}
\hline Article History & ABSTRACT \\
\hline Received: 12.11.2020 & ATTITUDES OF LEVEL IV PIM TRAINING PARTICIPANTS TOWARDS \\
Received in revised form: & BLENDED LEARNING LEARNING MODEL. The development of Information \\
24.12.2020 & Technology is one of the driving forces behind e-government adoption. \\
Accepted: 07.01 .2021 & Nevertheless, the learning process of Government officials capability creation \\
Available online: 29.01 .2021 & is already conceivably undertaken electronically. This study aims to discover \\
& perceptions of government officials towards mixed learning in year 2018 group \\
& of 40 DIKLAT PIM IV training participants. This research takes a quantitative \\
& approach using descriptive statistics and Analysis of Variance as analysis tool. \\
& The T-test tested the first testing hypotheses. A one-way ANOVA was \\
& conducted to test second hypotheses. The outcome indicates a constructive \\
& attitude towards blended learning among DIKLAT PIM IV 2018 training \\
& participants. Gender-based attitudes about blended learning are substantially \\
different.
\end{tabular}

KEYWORDS: Attitude, Blended Learning, Gender, Government Officials.

$\begin{array}{cl}\text { DOI: } 10.30653 / 001.202151 .144 & \begin{array}{l}\text { This is an open access article distributed under the terms of the Creative Commons } \\ \text { Attribution } 4.0 \text { International License, which permits unrestricted use, distribution, and } \\ \text { reproduction in any medium, provided the original work is properly cited. } \\ \text { @ } 2021 \text { Ratnaningsih Hidayati, Nadya Megawati Rachman, Caterin Magdalena } \\ \text { Simamora. }\end{array}\end{array}$

\section{PENDAHULUAN}

Pusat Pendidikan dan Pelatihan Perdagangan (Pusdiklat Perdagangan) merupakan salah satu divisi dari Kementerian Perdagangan Republik Indonesia yang bertugas memberikan pelatihan kepada aparatur Kementerian Perhubungan. Saat ini program pelatihan yang diselenggarakan oleh Pusdiklat Perdagangan dilakukan dengan metode konvensional yang masih bertumpu pada pertemuan tatap muka di dalam kelas. Di sisi lain, banyaknya pelatihan yang dilakukan belum mampu memenuhi minat para pemangku kepentingan.

Kemajuan teknologi informasi saat ini telah memungkinkan dilakukannya pembelajaran jarak jauh berbasis internet secara efektif dan efisien. Oleh karena itu, pelatihan berbasis internet dalam bentuk blended learning atau e-learning merupakan

${ }^{1}$ Corresponding author's address: Pusat Pendidikan dan Pelatihan Perdagangan, Kementerian Perdagangan; Jl. Abdul Wahab No. 38 Kedaung Sawangan Depok, Indonesia; Email: ratna.hidayati@kemendag.go.id 
praktik yang layak dan menjadi solusi dalam mengembangkan program pelatihan di Pusdiklat Perdagangan.

Pemerintah telah mengeluarkan Peraturan LAN tentang penyelenggaraan diklat kepemimpinan dengan kurikulum baru. Hal ini membawa dampak bahwa lembaga diklat harus siap dengan infrastruktur dan fasilitas dasar internet. Kurikulum pelatihan kepemimpinan mensyaratkan proses pembelajaran dilakukan melalui pendekatan pembelajaran klasikal dan non klasikal. Pembelajaran konvensional dilaksanakan di Pusdiklat sedangkan pada pembelajaran non klasikal peserta kembali ke institusi masingmasing untuk berkomunikasi dan melaksanakan proyek perubahan (proyek perubahan). Selama proses non klasikal, peserta difasilitasi dengan beberapa pendampingan dengan pembina masing-masing. Coach merupakan fasilitator pelatihan yang tugasnya menstimulasi proses berfikir dan segala sumber daya yang dimiliki peserta, membangun proses kesadaran diri dan membuat berbagai strategi untuk memecahkan masalah yang mereka hadapi dengan metode yang telah dibuktikan melalui penelitian. Salah satu pendekatan dalam melaksanakan proses coaching adalah dengan menerapkan model pembelajaran blended-learning.

Pengembangan kapasitas aparatur pemerintah melalui blended learning ini tidak terbatas pada pembelajaran non-klasikal; dalam hal ini, pembelajaran klasikal penggunaan pembelajaran berbasis teknologi informasi dimungkinkan dalam format blended learning. Peraturan Pemerintah yaitu Peraturan Kepala LAN Nomor 5 tahun 2015 tentang Pedoman Pelaksanaan Pelatihan Fasilitator Tingkat III dan IV (Pedoman Penyelenggaraan Pelatihan Kewidyaiswaraan Substansi Pendidikan dan Pelatihan Kepemimpinan Tingkat III dan IV) menyatakan bahwa salah satu kompetensi tutor pengajar yang harus yang dimiliki oleh fasilitator diklat adalah mampu menerapkan metodologi pembelajaran yang inovatif sesuai dengan mata pelajaran diklat. Pembelajaran berbasis web dengan pemanfaatan teknologi informasi dinilai merupakan terobosan inovatif yang layak untuk dimanfaatkan karena peserta diklat mampu memperoleh sumber belajar yang lebih komprehensif selain yang diberikan oleh fasilitator diklat di dalam kelas.

Sampai saat ini ada definisi yang tegas tentang istilah "e-learning". Namun, (Hartshorne \& Ajjan, 2009) menekankan bahwa Internet telah menjadi cara penting untuk menyediakan sumber daya untuk penelitian dan pembelajaran bagi guru dan siswa untuk berbagi dan memperoleh informasi. (Wentling et al., 2000) menjelaskan bahwa blended learning mengacu pada pencapaian dan penggunaan pengetahuan yang sebagian besar difasilitasi dan didistribusikan dengan cara elektronik. E-learning mengandalkan komputer dan jaringan baik itu jaringan internal atau global, tetapi itu kemungkinan besar itu akan berkembang menjadi sistem yang terdiri dari berbagai saluran seperti nirkabel dan satelit, dan teknologi seperti telepon seluler

Twigg (2002) dalam (Arkorful \& Abaidoo, 2015) menggambarkan pendekatan elearning sebagai fokus pada pelajar selain gayanya yang melibatkan sistem yang interaktif, berulang, swa-pacu (self-paced), dan dapat dikustomisasi. Welsh et.al. (2003) juga merujuk istilah tersebut karena penggunaan teknologi jaringan, terutama melalui internet, untuk menghasilkan informasi dan instruksi pembelajaran kepada khalayak.

Commission of European Communities (2001) menjelaskan e-learning sebagai penggunaan teknologi multimedia baru dan Internet untuk meningkatkan kualitas pembelajaran dengan mempermudah akses ke fasilitas dan layanan. E-learning mungkin juga meningkatkan pertukaran dan kolaborasi yang jauh. (OECD, 2005) mendefinisikan 
blended learning sebagai penggunaan teknologi informasi dan komunikasi dalam berbagai proses pendidikan untuk mendukung dan meningkatkan proses pembelajaran di lembaga pendidikan tinggi (di universitas atau lembaga pelatihan) dan termasuk penerimaan teknologi informasi dan komunikasi sebagai tambahan untuk ruang kelas tradisional, pembelajaran online atau kombinasi dari dua mode pembelajaran

Dalam konteks pendidikan tinggi atau perguruan tinggi, menurut (Tao et al., 2006), suasana baru pembelajaran yang difokuskan pada jaringan elektronik ini memungkinkan peserta didik di universitas untuk mendapatkan dukungan pribadi dan juga memiliki jadwal pembelajaran yang lebih sesuai untuk mereka serta terpisah dari peserta didik yang berbeda. Ini memfasilitasi interaksi dan kolaborasi yang tinggi antara instruktur atau akademisi dan rekan sejawat daripada suasana tradisional untuk belajar. Liaw dkk. (2007) dalam (Arkorful \& Abaidoo, 2015) menjelaskan e-learning di perguruan tinggi yang ditandai dengan pemanfaatan konstruk multimedia menciptakan metode pembelajaran yang lebih aktif, menarik perhatian dan menyenangkan. Konstruksi utama yang telah menciptakan e-learning sebagai teknologi akademis yang paling menjanjikan, menurut (Hammer \& Champy, 2009) dan (Tao et al., 2006), terdiri dari layanan, biaya, kualitas, dan kecepatan. E-learning akan memberdayakan siswa di tingkat akademis yang lebih tinggi untuk memperoleh pendidikan mereka sementara pada saat yang sama mempelajari tujuan mereka juga sebagai mempertahankan karir mereka sendiri, tanpa perlu mengikuti jadwal yang kaku (Bottorff, P. C., \& Lowe, 2007). Sejalan dengan Kartha (2006), yang percaya bahwa kuantitas kursus online telah meningkat pesat sebagai hasil dari keuntungan yang diperoleh setiap pelajar dan universitas.

Beberapa peneliti telah menemukan hubungan antara usia dengan pembelajaran online dan preferensi siswa untuk jenis kegiatan pembelajaran online. (Koh \& Lim, 2012) mempelajari dampaknya terhadap kinerja akademis setelah perangkat berasis web untuk kerja kolaboratif digunakan dalam kursus sains teknik universitas. Siswa dalam kelas tersebut berusia antara delapan belas sampai dua puluh enam tahun, dan oleh karena itu usia rata-rata para sarjana dalam kursus tersebut adalah 21,18. Para peneliti menemukan bahwa dengan bertambahnya usia siswa, nilai siswa pada tugas akhir juga meningkat. Studi ini mendukung tesis bahwa nilai siswa yang lebih tua lebih tinggi daripada siswa yang lebih muda pada ukuran kinerja akademis setelah perangkat berasis web digunakan dalam kursus.

Koh dan Lim (2012) mempelajari hubungan antara usia, kinerja tutorial, dan interaksi sosial yang diberikan oleh alat kolaboratif berbasis web yang sangat berbeda. Sebagai usia siswa menurun, preferensi siswa untuk alat yang memungkinkan untuk sarana online tambahan komunikasi ditingkatkan. Siswa yang lebih muda mendapat nilai lebih tinggi pada tugas setelah mereka mungkin mengobrol online, memposting foto, berbagi cerita, dan berbagi komentar.

Beberapa penelitian menunjukkan bahwa pria dan wanita berbeda pendapat dalam interaksi mereka dengan teknologi. Dorman, 1998; Kayany dan Yelsma, 2000; Adamus et al., 2009 melaporkan pengertian laki-laki yang lebih cenderung menggunakan komputer dan media baru (Cuadrado-García et al., 2010). Sebaliknya, Cuadrado-García et al. (2010) melakukan analisis ANOVA faktor satu arah dan antar-individu untuk menguji adanya perbedaan yang signifikan dalam penilaian dan penggunaan kegiatan e-learning oleh siswa laki-laki dan perempuan dalam konteks proyek online antara dua universitas Eropa. Akibatnya, ada sedikit perbedaan antara siswa laki-laki dan perempuan dalam penggunaan e-learning serta motivasi dan kepuasan mereka. Dalam penelitian lain 
menyelidiki efektivitas pendekatan pembelajaran campuran. Hasil sebagian besar menunjukkan bahwa blended learning memenuhi kebutuhan pendidikan siswa, seperti meningkatkan kenyamanan dan fleksibilitas serta mengembangkan pemikiran kritis (Ja'ashan, 2015).

\section{METODE}

Penelitian ini dilakukan dengan pendekatan metodologi kuantitatif. Populasi peserta pelatihan berjumlah 40 orang yang disurvei pada penelitian ini. Populasi ini mencakup peserta dari berbagai kelompok usia dan jenis kelamin. Kuesioner dilakukan melalui survei berbasis web yaitu www.surveymonkey.com. Kuesioner tersebut adalah kuesioner dengan 15 pertanyaan yang mengukur sikap terhadap blended learning (Cheng, 2006). Skala ini terdiri dari tiga dimensi yang mengukur, dalam sistem pendidikan elektronik, perspektif individu, efek pembelajaran, dan pengelolaan kelas. Dalam studi Cheng nilai alfa dari tingkat reliabilitas yang dilaporkan adalah 0,8076.

Pertanyaan dan Hipotesis Penelitian

1. Apakah terdapat sikap negatif yang signifikan terhadap blended learning dari peserta pelatihan?

H0: Tidak terdapat sikap negatif yang signifikan terhadap blended learning dari peserta pelatihan

H1: Terdapat sikap negatif yang signifikan terhadap blended learning dari peserta pelatihan

2. Apakah terdapat perbedaan yang signifikan sikap terhadap blended learning berbasis gender?

H0: Tidak ada perbedaan yang signifikan secara statistik dalam sikap terhadap blended learning berdasarkan kelompok gender

H1: Akan ada perbedaan yang signifikan secara statistik sikap terhadap blended learning berdasarkan kelompok gender

\section{HASIL DAN PEMBAHASAN}

\section{Analisis Deskriptif}

Dari 40 peserta pelatihan diperoleh respon sebanyak 100\%; semua peserta pelatihan mengisi kuesioner melalui tautan yang dibagikan di Sistem Manajemen Pembelajaran Edmodo. Beberapa peserta telah memiliki pengalaman mengikuti pembelajaran berbasis online yang diadakan oleh beberapa institusi yaitu WTO, Edx, Coursera, Vrije University, dan lain-lain. Data dikelompokkan menurut faktor yang berbeda seperti jenis kelamin dan usia (Tabel 1 dan 2).

Tabel 1. Statistik Deskriptif Berdasarkan Gender

\begin{tabular}{lll}
\hline Gender & Jumlah & Persentase \\
\hline Laki-laki & 23 & 57.5 \\
Perempuan & 17 & 42.5 \\
Jumlah & 40 & 100 \\
\hline
\end{tabular}

Sumber: Data primer, 2018 
Tabel 2. Statistik Deskriptif Berdasarkan Usia

\begin{tabular}{ll}
\hline & Usia \\
\hline Minimum & 29 \\
Maksimum & 53 \\
Rerata & 36,7561 \\
Standar Deviasi & 4,30569 \\
\hline
\end{tabular}

Sumber: Data primer, 2018

\section{Pembahasan}

\section{Sikap terhadap Blended Learning}

Uji-T digunakan untuk menguji hipotesis penelitian untuk membandingkan skor rata-rata dari dua kelompok orang atau kondisi yang berbeda. Dalam penelitian ini kami membandingkan skor rata-rata dengan rata-rata skala hipotetis.

H0: Ada sikap negatif yang signifikan terhadap blended learning dari peserta pelatihan

H1: Tidak ada sikap negatif yang signifikan terhadap blended learning dari peserta pelatihan

Tabel 3. Statistik Deskriptif

\begin{tabular}{llllllllll}
\hline & Mean & $\begin{array}{l}\text { Standar } \\
\text { Error }\end{array}$ & Median & Mode & $\begin{array}{l}\text { Standar } \\
\text { Deviasi }\end{array}$ & $\begin{array}{l}\text { Varians } \\
\text { Sampel }\end{array}$ & Range & Min & Max \\
\hline Q1 & 3,0976 & 0,0976 & 3 & 3 & 0,6247 & 0,3902 & 2 & 2 & 4 \\
Q2 & 3,2683 & 0,0857 & 3 & 3 & 0,5488 & 0,3012 & 2 & 2 & 4 \\
Q3 & 3,1951 & 0,0871 & 3 & 3 & 0,5577 & 0,3110 & 2 & 2 & 4 \\
Q4 & 3,1707 & 0,0917 & 3 & 3 & 0,5875 & 0,3451 & 2 & 2 & 4 \\
Q5 & 3,2439 & 0,0840 & 3 & 3 & 0,5376 & 0,2890 & 2 & 2 & 4 \\
Q6 & 3,1707 & 0,0848 & 3 & 3 & 0,5433 & 0,2951 & 2 & 2 & 4 \\
Q7 & 3,2250 & 0,0839 & 3 & 3 & 0,5305 & 0,2814 & 2 & 2 & 4 \\
Q8 & 3,1220 & 0,1059 & 3 & 3 & 0,6781 & 0,4598 & 3 & 1 & 4 \\
Q9 & 3,2439 & 0,0764 & 3 & 3 & 0,4889 & 0,2390 & 2 & 2 & 4 \\
Q10 & 3,0976 & 0,0765 & 3 & 3 & 0,4901 & 0,2402 & 2 & 2 & 4 \\
Q11 & 3,0000 & 0,1048 & 3 & 3 & 0,6708 & 0,4500 & 2 & 2 & 4 \\
Q12 & 3,0732 & 0,1012 & 3 & 3 & 0,6477 & 0,4195 & 3 & 1 & 4 \\
Q13 & 3,2927 & 0,0873 & 3 & 3 & 0,5587 & 0,3122 & 2 & 2 & 4 \\
Q14 & 3,2683 & 0,0989 & 3 & 3 & 0,6334 & 0,4012 & 2 & 2 & 4 \\
Q15 & 3,1707 & 0,1042 & 3 & 3 & 0,6672 & 0,4451 & 3 & 1 & 4 \\
\hline
\end{tabular}

Sumber: Data Primer, 2018

Model pembelajaran blended learning merupakan hal yang relatif baru dalam konteks Indonesia. Meskipun demikian, para peserta diklat sudah tidak asing lagi dengan sistem ini, khususnya pada bagian e-learning, karena mereka telah mendaftar dan diterima di kelas e-learning yang diadakan oleh institusi lain. Oleh karena itu, penulis berharap tidak ada sikap negatif yang signifikan terhadap blended learning. Dengan kata lain, peserta siap untuk belajar dengan sistem baru ini. Statistik deskriptif untuk item skala disajikan pada tabel 3 dan kemudian diuji apakah skor item berbeda secara signifikan dari mean skala teoritis (4 poin pada skala tipe Likert). 
Tabel 4. Hasil Uji T

\begin{tabular}{llllll}
\hline & Mean & Variance & $\mathrm{df}$ & $\mathrm{t}$ Stat & $\mathrm{P}(\mathrm{T}<=\mathrm{t})$ two-tail \\
\hline Q1 & 3,097561 & 0,390244 & 40 & 6,125 & $3,15334 \mathrm{E}-07$ \\
Q2 & 3,268293 & 0,30122 & 40 & 8,963489 & $4,10792 \mathrm{E}-11$ \\
Q3 & 3,195122 & 0,310976 & 40 & 7,981596 & $8,37265 \mathrm{E}-10$ \\
Q4 & 3,170732 & 0,345122 & 40 & 7,310624 & $6,9525 \mathrm{E}-09$ \\
Q5 & 3,243902 & 0,289024 & 40 & 8,860142 & $5,61269 \mathrm{E}-11$ \\
Q6 & 3,170732 & 0,295122 & 40 & 7,905694 & $1,06156 \mathrm{E}-09$ \\
Q7 & 3,225 & 0,28141 & 40 & 8,643667 & $1,33944 \mathrm{E}-10$ \\
Q8 & 3,121951 & 0,459756 & 40 & 5,873331 & $7,12239 \mathrm{E}-07$ \\
Q9 & 3,243902 & 0,239024 & 40 & 9,742868 & $4,07141 \mathrm{E}-12$ \\
Q10 & 3,097561 & 0,240244 & 40 & 7,806349 & $1,44956 \mathrm{E}-09$ \\
Q11 & 3 & 0,45 & 40 & 4,772607 & $2,43664 \mathrm{E}-05$ \\
Q12 & 3,073171 & 0,419512 & 40 & 5,666353 & $1,39119 \mathrm{E}-06$ \\
Q13 & 3,292683 & 0,312195 & 40 & 9,084026 & $2,85911 \mathrm{E}-11$ \\
Q14 & 3,268293 & 0,40122 & 40 & 7,76654 & $1,64273 \mathrm{E}-09$ \\
Q15 & 3,170732 & 0,445122 & 40 & 6,437263 & $1,14826 \mathrm{E}-07$ \\
\hline
\end{tabular}

Sumber: Data Primer, 2018

Tabel 4 menunjukkan bahwa semua skor pada semua item secara signifikan lebih tinggi daripada rata-rata teoritis skala. Hasil ini mendukung $\mathrm{H} 0$ yang menyatakan bahwa peserta diklat tidak memiliki sikap negatif terhadap pendekatan blended learning. Dari temuan penelitian ini, dapat disimpulkan bahwa terdapat sikap yang baik terhadap blended learning pada peserta pelatihan PIM IV 2018. Hal ini juga ditegaskan oleh (Miliszewska, 2008) yang menyimpulkan bahwa siswa secara umum memiliki sikap positif terhadap model pembelajaran blended learning, mengingat bahwa mereka masih menggunakan pendekatan tradisional sebagai yang paling sederhana untuk berdiskusi tentang konten pembelajaran dan untuk menerima umpan balik dari guru. Pengajaran tradisional harus disesuaikan dengan kebutuhan siswa baru yang "melek digital". Temuan penelitian menegaskan bahwa fasilitator memperoleh keuntungan relatif cepat dan mudah, sehingga secara tidak langsung mereka menunjukkan prinsip kolaborasi pengajaran dalam pekerjaan pedagogis. Selain itu, model blended learning dapat meningkatkan hasil belajar, meningkatkan kepuasan siswa, dan membuat mata pelajaran lebih dapat diakses oleh siswa yang lebih luas (KM Eshreteh \& Hisham Siaj, 2017).

\section{Sikap terhadap Blended Learning berdasarkan kelompok gender}

Untuk menguji hipotesis kedua, dilakukan uji ANOVA satu arah. Hasilnya disajikan pada Tabel 5 .

Tabel 5. Hasil Uji ANOVA

\begin{tabular}{lllllll} 
ANOVA & \multicolumn{1}{l}{} \\
\hline Source of Variation & SS & df & MS & F & P-value & F crit \\
\hline Between Groups & 280,36 & 1 & 280,36 & 10,35 & 0,00265 & 4,0982 \\
Within Groups & 1029,54 & 38 & 27,093 & & & \\
Total & 1309,9 & 39 & & & & \\
\hline \multicolumn{7}{c}{ Sumber: data primer 2018, dianalisis }
\end{tabular}

Hasil penelitian menunjukkan bahwa terdapat perbedaan yang signifikan sikap terhadap blended learning antara peserta laki-laki dan perempuan. Analisis of Varians (ANOVA) menghasilkan nilai $\mathrm{P}$ di bawah nilai kritis 0,05 dan $\mathrm{F}$ di atas nilai $\mathrm{F}$ kritis. 
Penelitian (Koohang, 2004) tentang gender, menemukan bahwa laki-laki lebih cenderung menggunakan lingkungan blended learning daripada perempuan. Ini juga sejalan dengan temuan (Birbal et al., 2018), bahwa hasil uji-t menunjukkan bahwa terdapat perbedaan yang signifikan antara sikap pria dan wanita terhadap pembelajaran online. Siswa lakilaki memiliki sikap yang lebih positif terhadap pembelajaran online daripada siswa perempuan. Al-Fadhli, 2008 juga melaporkan signifikan yang kuat dalam sikap siswa terhadap e-learning sesuai dengan gender. Skor rata-rata siswa perempuan mengungguli siswa laki-laki di semua bidang. Siswa perempuan terlihat positif dalam mengevaluasi elemen mata kuliah. (Abou Naaj et al., 2012) dalam sebuah studi tentang mengevaluasi kepuasan siswa dengan pembelajaran campuran dalam lingkungan yang dipisahkan berdasarkan gender menemukan bahwa siswa laki-laki lebih puas dengan pembelajaran campuran daripada siswa perempuan. Menurut (Meyer, 2003), gender berbeda dan memainkan peran penting dalam interaksi dan pertukaran online yang mirip dengan kenyataan. Dia telah menunjukkan bahwa wanita lebih simpatik, ramah, dan sopan. Namun, pria lebih mengendalikan pertukaran online, lebih ingin tahu, dan tegas.

Dalam penelitian lain, fakta ini kontras dengan (Cuadrado-García et al., 2010) bahwa hanya terdapat sedikit perbedaan antara siswa laki-laki dan perempuan dalam penggunaan pembelajaran campuran dan motivasi serta kepuasan mereka dalam konteks Universitas Eropa. (Al Zumor et al., 2013) dalam studi siswa EFL Mesir juga mengambil posisi yang sama, jenis kelamin siswa memiliki pengaruh yang signifikan terhadap gaya belajar siswa tetapi tidak berpengaruh pada kepuasan mereka dengan penyampaian materi berbasis web. (Askar et al., 2008) melaporkan tidak ada perbedaan signifikan yang ditemukan secara statistik antara perempuan dan laki-laki sehubungan dengan kepuasan pada pembelajaran campuran; namun skor perempuan secara statistik lebih tinggi daripada laki-laki untuk lingkungan tatap muka. (Adas \& Shmais, 2011) juga menemukan tidak ada perbedaan yang signifikan dalam hal jenis kelamin meskipun rata-rata tertinggi berpihak pada perempuan.

\section{SIMPULAN}

Penelitian ini berkontribusi dalam mengungkap persepsi dan sikap peserta didik tentang blended learning bagi Peserta Pelatihan PIM IV. Hasil penelitian ini menggambarkan kepuasan peserta didik dengan Blended Learning yang terlihat dari tidak adanya sikap negatif terhadap pendekatan ini karena hal tersebut meningkatkan pelatihan menjadi lebih kolaboratif, interaktif dan menarik. Selain itu, hal ini mencerminkan interaksi antara fasilitator dan peserta, serta memberi mereka cukup waktu untuk melakukan tugasnya. Jadi, peserta didorong untuk bertanggung jawab atas proses pembelajaran mereka sendiri dan peserta didik dapat memutuskan kapan dan bagaimana menggunakan sumber daya yang disediakan. Hal ini dapat mendorong transformasi di bidang Pendidikan dan pelatihan dengan menciptakan perubahan paradigma dari pendidikan yang berpusat pada guru dan berbasis teks ke Pendidikan dan pelatihan yang berpusat pada peserta di mana peserta pelatihan bekerja secara kolaboratif, membangun pengetahuan mereka sendiri dan meningkatkan pemikiran kritis mereka.

Simpulan lain dari penelitian ini adalah terdapat perbedaan yang signifikan antara kelompok gender laki-laki dan perempuan terhadap penerapan model blended learning pada kelas Diklat Pim IV tahun 2018 di Pusdiklat Perdagangan. Peneliti menyarankan untuk melakukan penelitian lanjutan dengan tujuan mengetahui secara lebih rinci 
mengenai perbedaan sikap antara kedua kelompok gender terhadap adopsi model pembelajaran blended learning. Selain itu, berdasarkan analisis data hasil penelitian, sangat disarankan untuk mengadopsi Blended Learning ini untuk pelatihan lain yang diadakan oleh Pusdiklat Perdagangan.

\section{REFERENSI}

Abou Naaj, M., Nachouki, M., \& Ankit, A. (2012). Evaluating student satisfaction with blended learning in a gender-segregated environment. Journal of Information Technology Education: Research, 11(1), 185-200.

Adas, D., \& Shmais, W. A. (2011). Students' perceptions towards blended learning environment using the OCC. Humanities, 25(6), 1681-1710.

Al-Fadhli, S. (2008). Students' Perceptions of E-learning in Arab Society: Kuwait University as a case study. E-Learning and Digital Media, 5(4), 418-428.

Al Zumor, A. W. Q., Al Refaai, I. K., Eddin, E. A. B., \& Al-Rahman, F. H. A. (2013). EFL Students' Perceptions of a Blended Learning Environment: Advantages, Limitations and Suggestions for Improvement. English Language Teaching, 6(10), 95-110.

Arkorful, V., \& Abaidoo, N. (2015). The role of e-learning, advantages and disadvantages of its adoption in higher education. International Journal of Instructional Technology and Distance Learning, 12(1), 29-42.

Askar, P., Altun, A., \& Ilgaz, H. (2008). Learner satisfaction on blended learning. Krakow: Eleader.

Birbal, R., Ramdass, M., \& Harripaul, M. C. (2018). Student teachers' attitudes towards blended learning. Journal of Education and Human Development, 7(2), 9-26.

Bottorff, P. C., \& Lowe, S. L. (2007). Student perceptions and opinions toward blended learning in the college environment. Academy of Educational Leadership Journal, 11(2), 13-30.

Cheng, K. (2006). A research study on students' level of acceptance in applying e-learning for business courses-a case study on a technical college in Taiwan. Journal of American Academy of Business, 8(2), 265-270.

Commission of European Communities. (2001). The E-learning action plan: Designing tomorrow's education. Commission of the European Communities.

Cuadrado-García, M., Ruiz-Molina, M.-E., \& Montoro-Pons, J. D. (2010). Are there gender differences in e-learning use and assessment? Evidence from an interuniversity online project in Europe. Procedia-Social and Behavioral Sciences, 2(2), 367-371.

Hammer, M., \& Champy, J. (2009). Reengineering the Corporation: Manifesto for Business Revolution. Washington, DC: Summaries.com.

Hartshorne, R., \& Ajjan, H. (2009). Examining student decisions to adopt Web 2.0 technologies: theory and empirical tests. Journal of Computing in Higher Education, 21(3), 183.

Kartha, C. P. (2006). Learning business statistics: Online vs traditional. The Business Review, $5(1), 27-32$. 
KM Eshreteh, M., \& Hisham Siaj, A. (2017). Attitudes of english-major students and teachers towards using blended learning in the english department at Hebron University. International Journal of Research in English Education, 2(4), 51-65.

Koh, E., \& Lim, J. (2012). Using online collaboration applications for group assignments: The interplay between design and human characteristics. Computers $\mathcal{E}$ Education, 59(2), 481-496.

Koohang, A. (2004). Students' perceptions toward the use of the digital library in weekly web-based distance learning assignments portion of a hybrid programme. British Journal of Educational Technology, 35(5), 617-626.

Meyer, K. A. (2003). The web's impact on student learning. THE Journal, 30(10), 1-9.

Miliszewska, I. (2008). Transnational education programs: Student reflections on a fullyonline versus a hybrid model. In International Conference On Hybrid Learning And Education (pp. 79-90).

OECD. (2005). Blended learning in tertiary education. Retrieved form http://www.Oecd.Org/Education/Ceri/35991871.Pdf.

Tao, Y., Yeh, C. R., \& Sun, S. (2006). Improving training needs assessment processes via the Internet: system design and qualitative study. Internet Research, 16(4), 427-449.

Wentling, T. L., Waight, C., Gallagher, J., La Fleur, J., Wang, C., \& Kanfer, A. (2000). Elearning: a review of literature. Champaign, IL: University of Illinois at UrbanaChampaign. 